\title{
Organ Relationship Object
}

National Cancer Institute

\section{Source}

National Cancer Institute. Organ Relationship Object. NCI Thesaurus. Code C43511.

An org an relationship object describes relationships among organs. (caBIO) 